\title{
Fuzzy Memories of Enrique Hector Ruspini (1942-2019)
}

\author{
Rudolf Seising ${ }^{(\bowtie)}$ (D) \\ Research Institute for the History of Science and Technology, \\ Deutsches Museum, Museumsinsel 1, 80538 Munich, Germany \\ r.seising@deutsches-museum.de
}

\begin{abstract}
This paper is a personal obituary of Enrique Hector Ruspini, an extraordinary scientist, tireless researcher, a smart science organizer and a great man. It can only mention a few of his scientific and private interests, achievements and achievements.
\end{abstract}

Keywords: Enrique Ruspini $\cdot$ Lotfi Zadeh $\cdot$ Jim Bezdek $\cdot$ Fuzzy sets $\cdot$ Fuzzy clustering

\section{Introduction}

Enrique Hector Ruspini was an extraordinary scientist, a tireless researcher, an immensely interesting person, but above all, he was a good friend! I knew him for about 20 years, where we met very often and often ate and drank well. He loved good food and fine wine. When I was in California, I used to visit him in Palo Alto. The first time we met for lunch and an interview on 30 July 2002 in Palo Alto. He was then employed at the Stanford research Institute an I was with the University of Vienna in Austria. 7 years later, when I was an adjoint researcher in the European Centre for Soft Computing (ECSC) in Mieres, Asturias (Spain) he became a principal researcher at that center and we saw us almost daily. After he left the ECSC in 2013, we met at conferences and I visited him and his wife Susana in California when I was there in Berkeley with Lotfi Zadeh to work on the history of fuzzy set theory. Enrique introduced me to the Computational Intelligence Society (CIS) of IEEE and about 10 years ago he, Jim Bezdek and Jim Keller accepted me as a member of the CIS History Committee. Enrique suggested that I continue the series of video interviews with pioneers and other researchers of CI, which he, the two Jims and others had started earlier.

In 2017, I planned two trips to California and to Lotfi and Enrique. Enrique was invited to attend the dedication ceremony of the robot Shakey to the Computer History Museum in Mountain View at February 16. He offered to let me join him. It was a memorable event and we had the opportunity to view the entire exhibition (see Figs. 1 and 8). 
The next day I asked Enrique to accompany me to meet Lotfi and he agreed. Lotfi was already very weak then but we could talk for about an hour in threes over tea and cookies. It was the last time the two of them saw each other and I photographed them while they were talking (see Fig. 2).
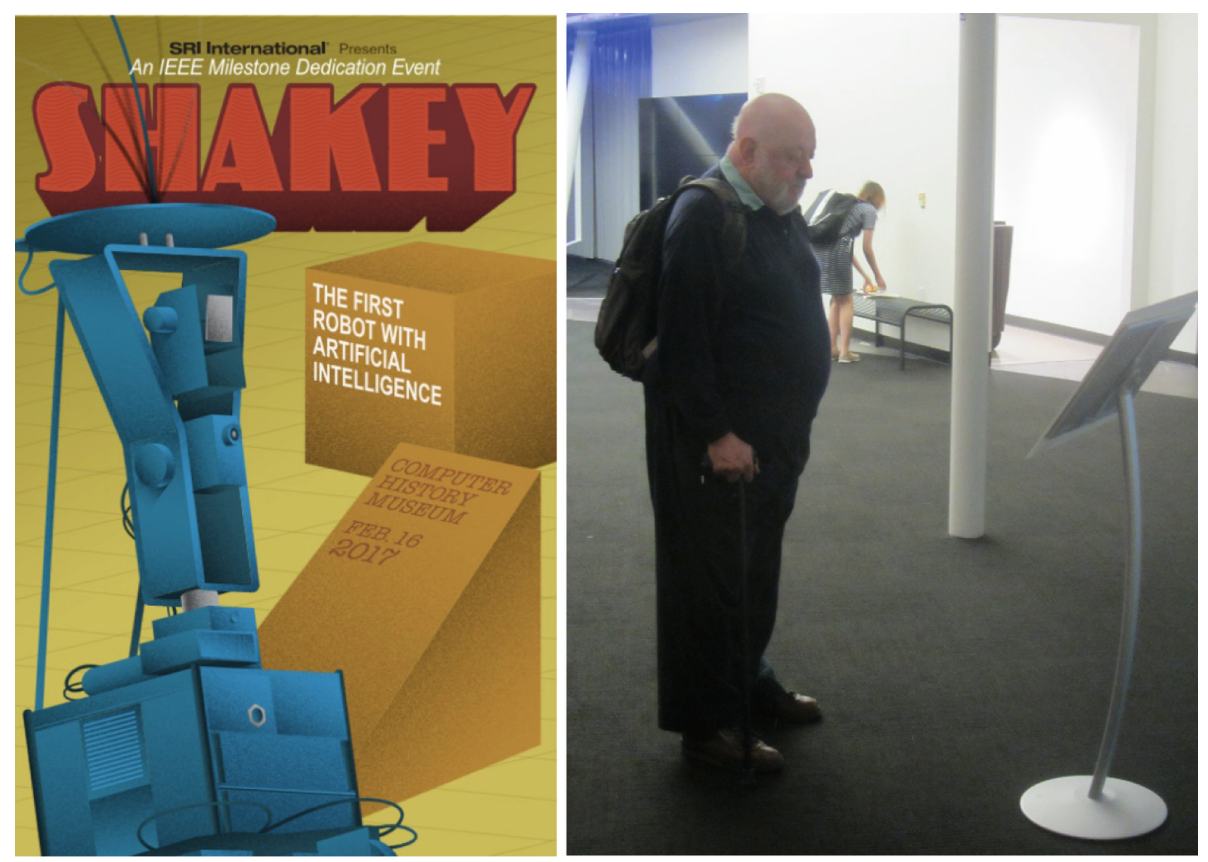

Fig. 1. left: Poster of the dedication ceremony of robot Shakey to the Computer History Museum right: Enrique at the Computer History Museum at February 16, 2017. (Photo: Rudolf Seising)

During my second visit in this year in Berkeley Lotfi passed away at 6 September. Some days later, at September 15, I drove to Palo Alto to interview Enrique at his home. The weather was nice, and we sat outside in his garden (see Fig. 3). The video of this interview is about an hour long but unfortunately, there was a lot of noise because of some birds in the garden and some planes in the air. Because of the strong noise, we have not yet included the video of the interview in the official collection of ieee.tv (https://ieeetv.ieee.org/channels/cis-oral-history?tab=allvideos), but it is available on the net: [1]. 


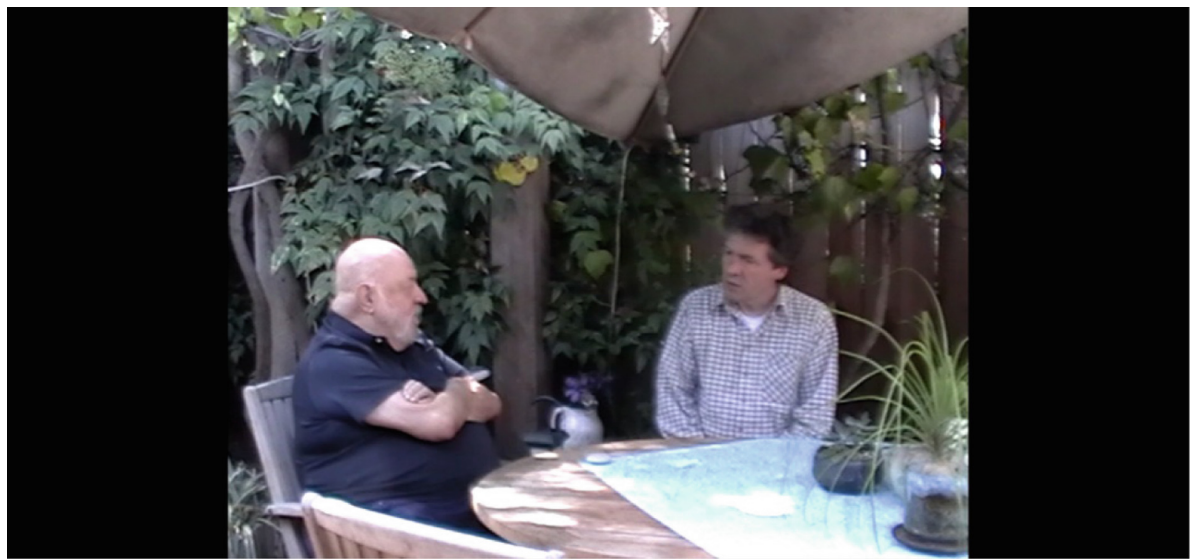

Fig. 2. Enrique and the author during the interview, September 15, 2017. (Photo: Rudolf Seising)

In 2018, Enrique was more and more suffering from a creeping illness. In this year, he should receive the Frank Rosenblatt Award "for fundamental contributions to the understanding of fuzzy logic concepts and their applications". However, he could not travel to Rio to receive this award. Fortunately, in June 2019, he could attend the 2019 IEEE International Conference on Fuzzy Systems in New Orleans, LA., and he could take the award (Fig. 4). Some weeks later, at October 15 in 2019 Enrique passed away.

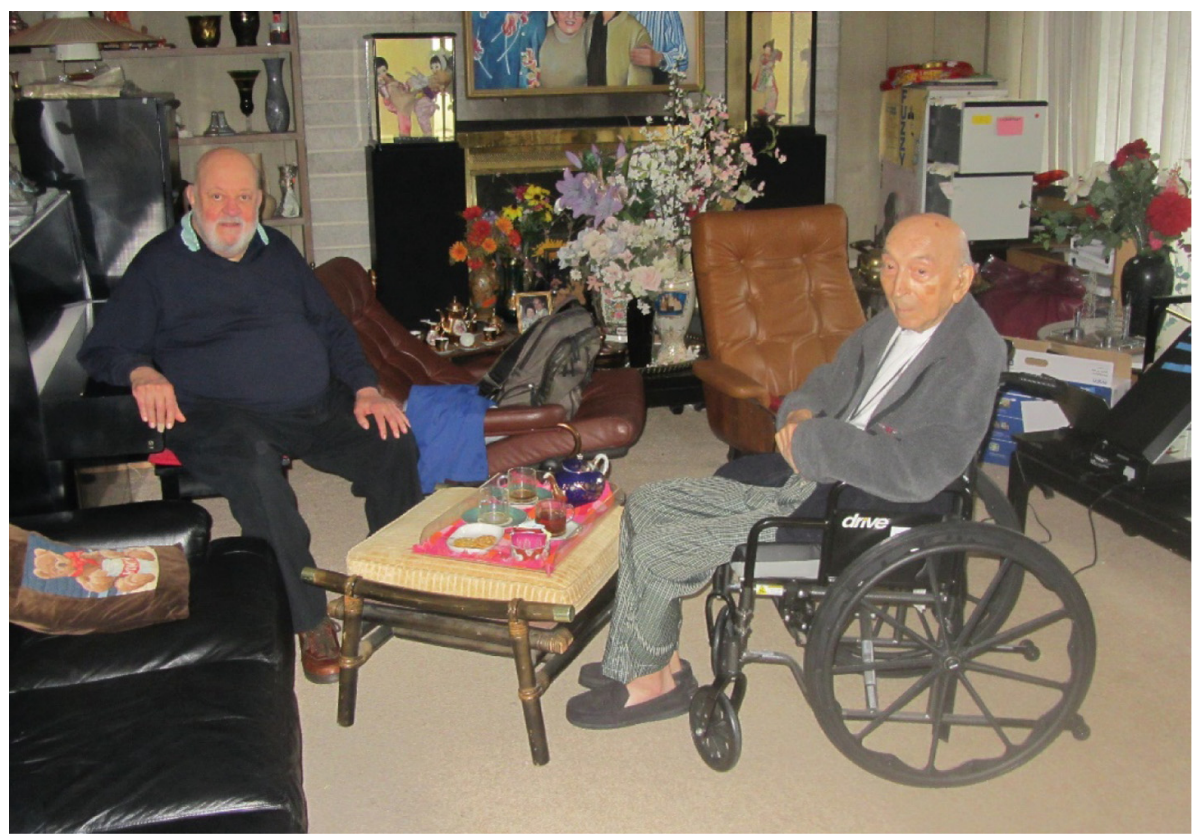

Fig. 3. Enrique's and Lotfi's meeting in February 2017 in Lotfi's house. (Photo: Rudolf Seising) 


\section{Facts and Data}

Enrique Hector Ruspini was born at December 20, 1942 in Buenos Aires, Argentina. He received the Licenciado en Ciencias Matemáticas (bachelor's degree in Mathematics) from the University of Buenos Aires, Argentina, in 1965 and his doctoral degree in System Science from the University of California at Los Angeles in 1977 [2]. Dr. Ruspini had held positions at the University of Buenos Aires, the University of Southern California, UCLA's Brain Research Institute, Hewlett-Packard Laboratories, the SRI International Artificial Intelligence Center, and the European Center for Soft Computing in Asturias (Spain). He was also a Distinguished Lecturer of the IEEE Computational Intelligence Society.

Dr. Ruspini, who was the recipient of the 2009 Fuzzy Systems Pioneer Award of the IEEE Computational Intelligence Society, received in 2004 the Meritorious Service Award of the IEEE Neural Networks Society for leading the transition of the Neural Networks Council into Society status. He was one of the founding members of the North American Fuzzy Information Processing Society (NAFIPS) and the recipient of that society's King-Sun Fu Award. He was an IFSA First Fellow, an IEEE Life Fellow and a former member of the IEEE Board of Directors and past President of the IEEE Neural Networks Council (now IEEE Computational Intelligence Society). In 2018, he was laureate of the IEEE Frank Rosenblatt Technical Field Award of the IEEE Computational Intelligence Society. He was a First Fellow of the International Fuzzy Systems Association, a Fulbright Scholar, a European Union Marie Curie Fellow, and a SRI International Fellow. Dr. Ruspini was the Editor in Chief (together with Piero P. Bonissone and Witold Pedrycz) of the Handbook of Fuzzy Computation. He was a member of the Advisory and Editorial Boards of numerous professional journals, e.g. IEEE Transactions on Fuzzy Systems, International Journal of Fuzzy Systems, International Journal of Uncertainty, Fuzziness, and Knowledge-Based Systems, Fuzzy Sets and Systems, Mathware and Soft Computing, and the Journal of Advanced Computational Intelligence and Intelligent Informatics. He published more than 100 research papers.

\section{The 1960s}

Enrique studied physics in Argentina when he encountered one of the first computers in his home country. He switched to mathematics and to the Instituto de Cálculo where he was concerned with the numerical solution of differential equations. He was interested in novel applications of computer science, e.g. in the field of biomedical engineering and in modeling and simulation in mathematical economics and he had a position paid by a group associated with the University of Buenos Aires that worked in a children's hospital. There was a group of neuroscientists doing research on neural signals and another group of colleagues was concerned with numerical taxonomy and classification of biological species. In 1964 he started planning to go abroad to get a $\mathrm{Ph} \mathrm{D}$. and then coming back to Argentina to get a professorship as it was usual. He wrote to many people and to Richard Ernest Bellman who as then professor of mathematics, electrical engineering and medicine. In 1965 or 1966, Enrique got an offer from Bellman to work 
at the Space Biology Laboratory in the Brain Research Institute at the University of South California (USC) that he accepted and in the academic year of 1966 he started a new job at USC in Los Angeles. Already in the late year of 1965 he read the seminal paper "Fuzzy Sets" by Lotfi Zadeh and at the same time, he was asked to use anyone of the new computer classification techniques. So, clustering came into his life at the same time as fuzzy sets and this was the beginning of fuzzy clustering. Very early, after he came to the US, he could publish his article "A New Approach to Clustering" [3].

Richard Bellman and his associate Robert Kalaba were coauthors of Zadeh's first memo on fuzzy sets ${ }^{1}$. Enrique remembered Bellman as a most interesting person and obviously one of the brightest applied mathematicians that ever lived. (8:25). There appeared many papers on control theory, differential systems and other areas. By Bellman, Kalaba and Ruspini in the 1960s. Enrique worked together mainly with Bob Kalaba and once in the late 1960s, when they were having lunch in the faculty club of USC Lotfi Zadeh came in to say Hello. Enrique had sent him a draft of his paper on fuzzy clustering and that afternoon they had some discussion on fuzzy clustering. This was the starting point of an association that lasted about half a century until Lotfi's death in 2017. In my interview, Enrique called Zadeh a great mentor ([1], 14:51).

\section{The 1970s and 1980s}

Many people received Enrique's paper on Fuzzy Clustering [2] and by people that were reluctant. In my interview, he said that this gave him an impulse to fight the unbelievers. He kept working on applications of fuzzy sets and at the same time on problems associated with medicine, and he also could combine both research areas e.g. in the paper on "A test of sleep staging systems in the unrestrained chimpanzee" in 1972 [5].

Jim Bezdek, who finished his Ph D thesis "Fuzzy Mathematics in Pattern Classification" in 1973 at Cornell University, Ithaca, New York, had read Enrique's paper on fuzzy clustering and he arranged an invitation to Enrique to give a talk at the Seventh Annual Meetings of The Classification Society, North American Branch. This meetings were held at the University of Rochester, May 23-25, 1976 an they both gave talks in the topical session "(4) Fuzzy clustering algorithms" [6]: Enrique lectured on "Fuzzy clustering as an optimum mapping between metric spaces" and Jim on" Feature selection for binary data with fuzzy ISODATA". Because many of the researchers in that society liked the simplicity and the power that the fuzzy approach brought to classification problems. Enrique and Jim were close friends from that time on. Jim interviewed Enrique during the IEEE Congress on Evolutionary Computing in Cancun, Mexico at June 20, 2011. This video of this interview is available as a video of the CIS Oral History project [7]. In 2015 I interviewed the two together via e-mail and the text of this interview is available online [8,9].

At the International Congress on Applied Systems Research and Cybernetics in Acapulco, Mexico, in 1980, Ron R. Yager had organized a number of sessions on fuzzy sets and fuzzy systems, possibility theory and special topics in systems research

\footnotetext{
${ }^{1}$ For details on the history of fuzzy sets, see the author's book [4].
} 
[10]. Here, Enrique and Ebrahim Mamdani met for the first time and he learned about his combination of rule-based systems and fuzzy control. On the flight returning to the USA from Acapulco Enrique Madan Gupta and Jim Bezdek were still fascinated by the impression of having their own forum for the exchange of ideas in the field of fuzzy sets. It was tempting to plan such a forum. Therefore, Jim and Enrique became founding members of the North American Fuzzy Information Processing Society (NAFIPS). Jim Bezdek organized the first NAFIP-meeting (in that time without the "s" at the end) in Logan, $\mathrm{Utah}^{2}$.

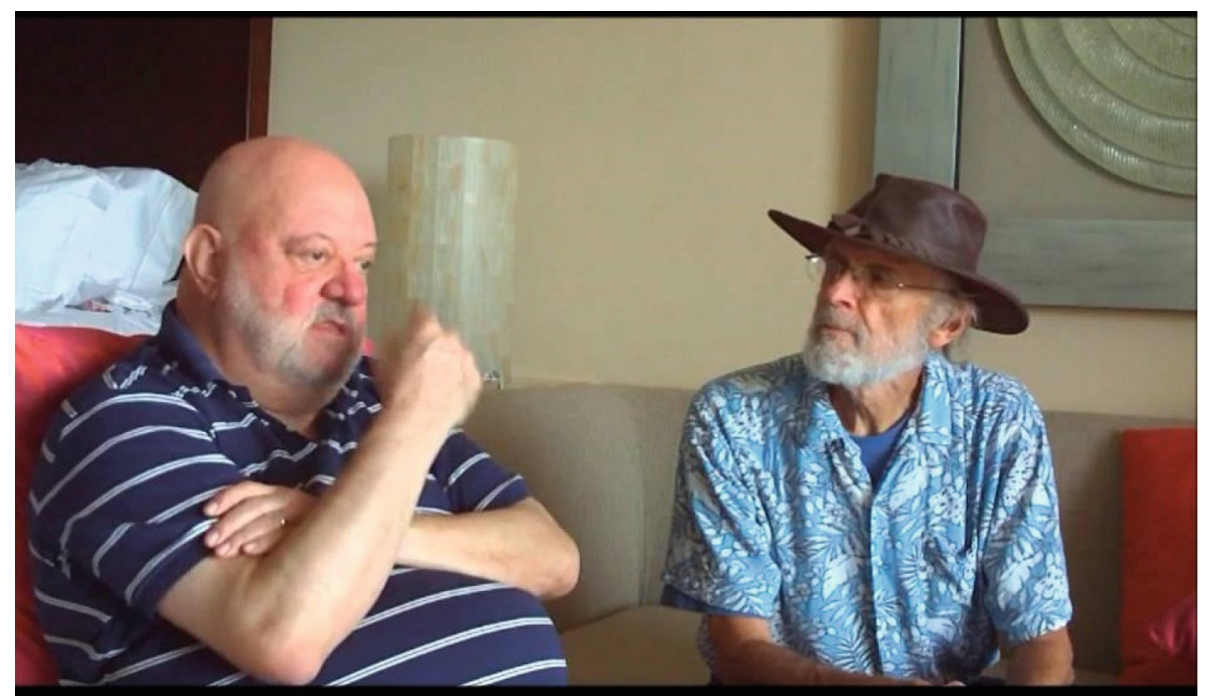

Fig. 4. Jim Bezdek interviews Enrique during the IEEE Congress on Evolutionary Computing in Cancun, Mexico June 20, 2011. (Photo from the video interview on the IEEE CIS history website, https://history.ieee-cis.sightworks.net/)

From Los Angeles Enrique moved to the Hewlett Packard Laboratories in Palo Alto in 1982 where he was concerned with databased systems and data analysis. However, in that time HP reorganized the company and Enrique cold not do as much research as he wanted to and therefore, he left HP to years later to join the SRI International's Artificial Intelligence Center, in Menlo Park, California, as a principal scientist. Sometime after, he had met John Lowrance, a principal scientist at SRI in Lotfi's seminar at UC Berkeley. Lowrance was very interested in evidential reasoning, especially in the theory of Dempster and Shafer, but also in other related ideas. Because of Enrique's skills in these epistemological issues, he hired him for SRI. With Alessandro Saffioti, and others Enrique developed a fuzzy controller, which they implemented in the autonomous mobile robot named FLAKEY, the successor to SHAKEY (see Fig. 5) [12, 13].

\footnotetext{
${ }^{2}$ See the whole story and a picture of some of the 41 participants to NAFIP-1- meeting, and the poster of this conference with many of the participants' signatures in [11].
} 
Enrique "confessed" in the interview that in the beginning he "didn't pay much that attention to the semantic questions" of fuzzy sets [...] but later, it became necessary. He was approached by people who wanted to better understand this theory and consequently he started research on "conceptual relations that synthesizes utilitarian and logical concepts" [14], on "the basic conceptual differences between probabilistic and possibilistic approaches" [15] and "On the Semantics of Fuzzy Logic" at SRI in the 1990s [16] ([1], 24:28-25:10). Many years later, he summarized these investigations in the contribution "On the Meaning of Fuzziness" for the two-volume collection "On Fuzziness. A Homage to Lotfi A. Zadeh" [17] Enrique worked for SRI International's AI Center for 25 years until he retired in 2009, and then he started a new phase at the ECSC in Spain.

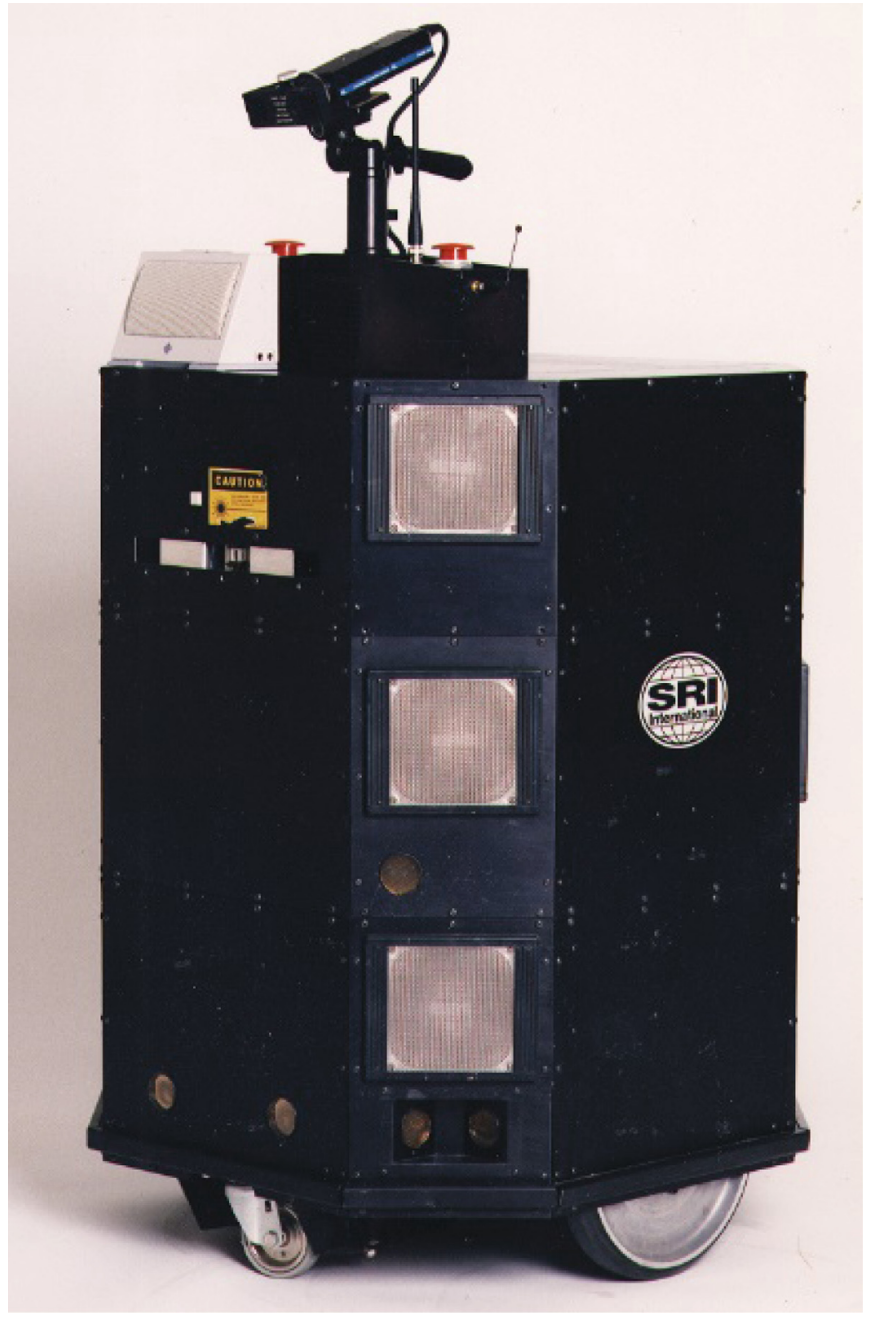

Fig. 5. Flakey the robot, developed around 1985 at SRI International 
When and how did Enrique arrive at the artificial neural networks (ANN)? In my interview, he said that in a sense he "kind of never had" (41:48). I insisted that he was the president of the IEEE Neural Networks Council, which is now IEEE Computational Intelligence Society and he answered: "Yeah, that's right but only because they incorporated fuzzy logic and evolutionary computation" ([1], 41:56). Enrique had never worked on artificial neural networks but he was a member of IEEE. At the end of the 1980s when there was the renaissance of ANN the IEEE formed the Neural Networks Committee and they organized a number of very successful conferences. Therefore, on November 17, 1989, IEEE decided to let the committee become the Neural Networks Council (NNC).

\section{From the 1990s Until Today}

In 1991, Jim Bezdek had called Enrique because the IEEE had signaled their interest in Fuzzy Logic to Lotfi Zadeh. They wanted to give researchers in Fuzzy Logic a major platform because there were a large number of hybrid methods combining neural networks and fuzzy logic. Lotfi had recommended contacting Jim, Piero and Enrique and they had achieved the establishment of the new series of IEEE International Conferences on Fuzzy Systems (FUZZ-IEEE) that continues until today. The first of these conferences took place in San Diego and the IEEE NNC sponsored this event with Lotfi as honorary chair, Jim as conference chair and Enrique as tutorial chair. The Second IEEE International Conference on Fuzzy Systems should be in San Francisco, in spring 1993; and because of organizational problems, it was held in conjunction with the 1993 International Conference on Neural Networks. Piero was program chair and Enrique was general chair of the conference. In my interview, he suspected that this was probably why his name was associated to neural networks ([1], 48:46). In 2001 he became president of the NNC and in this year he led the Council (NNC) into the Society (NNC). Two years later, in November 2003, it changed its name to its current one, the IEEE Computational Intelligence Society (CIS) and I asked in my interview who chose this name. Enrique answered: "we needed a name that was descriptive for the new society or the new council" - and here he emphasized that contrary to the opinion of many, it was not an easy way from this Neural Networks Council (NNC) to the Neural Networks Society (NNS) they formed on November 21, 2001 - "it took a long time" ([1], 49:52). He continued, "we needed a name that would differentiate us from just pure applied AI." (50:14). They were looking for ideas and then it was Jim Bezdek who suggested "computational intelligence" (CI).

In my interview Enrique said that "curacy enough until this day it is very difficult to explain to people what computational intelligence is without listing each one of the 
components" (fuzzy sets, artificial neural networks, evolutionary algorithms) (51:41) and he mentioned the political problems to be able to cooperate that into a description of our scope. He also mentioned that researcher in classical AI "have the same problem in describing what artificial intelligence is" ([1], 52:15).

Another term is soft computing (SC), introduced by Lotfi Zadeh in the 1990s. It was part of the name of both the BISC (Berkeley Initiative in Soft Computing) at the University of California and the ECSC (European Centre for Soft Computing) in Spain. The latter was the last academic institution Enrique worked for, and it turned out that way: In 2007 during the FUZZ-IEEE 2007 conference at the Imperial College in London Enric Trillas and Enrique had lunch together. After his retirement from academia in Spain Enric was an Emeritus Researcher at the ECSC and now, they discussed the eventualities of Enrique becoming a Principal Investigator at this place. Two years later, they realized this plan. In his contribution to the commemorative publication for Enric Trillas on his 75th birthday, Enrique tried to remember when the two might have first met:

"I do not believe that I met Enric before 1985 although it might have been a bit earlier. It was certainly after 1980 because I had not yet travel to Europe and I do not remember him visiting California before then. I recall, however, delivering a lecture at the School of Architecture of the Polytechnic University of Barcelona in the early 90's where he was present and where I took a picture of the audience with my brand new Cannon Photura: one of the first cameras featuring a fuzzy logic autofocus system. Our acquaintance dates, perhaps, to the time when I visited Spain to participate in the First IFSA Congress in Mallorca. I have tried to do a bit of detailed research about our initial meeting to give a more precise account of its circumstances but could not find any additional information to remove remaining ambiguities. The reader may certainly wonder why this quest for accuracy about either the author and its subject - both notorious examples of fuzzy scientists - matters at all. My obsession with this personal milestone, stems, however, from the realization that I was well along in my career before I met this remarkable man with whom I have had so many fruitful and continued interactions since our first encounter.

The photographic evidence shows that, by 1996, we had developed a friendship that allowed us to engage on merry pranks during lighter moments of serious scientific meetings, as seen in Fig. 6, when we posed as the never finished statues of a magnificent building originally constructed to house a technical labor university." [18].

Supported by the Foundation for the Advancement of Soft Computing, which was a private non-profit foundation, the ECSC was launched by the beginning of the year 2006. The most important goal of the center was the basic and applied research in soft computing and the technology transfer in industrial applications of intelligent systems design for the resolution of real-world problems. For almost ten years, the Center was a meeting point for experts in CI and SC all over the world. 


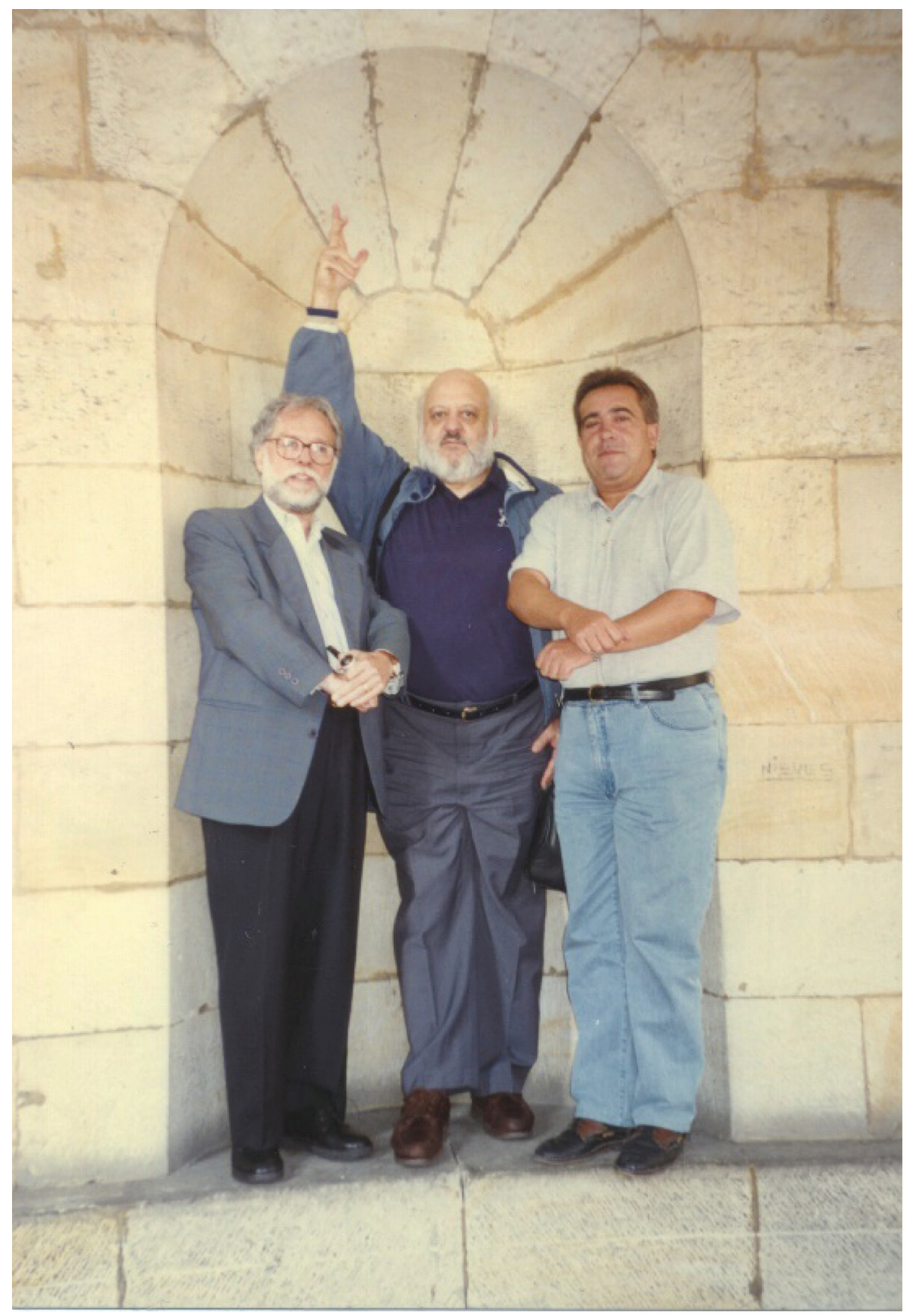

Fig. 6. "Lost" statues at the Universidad Laboral de Gijon, Asturias, Spain, 1996: Enric Trillas, Enrique Ruspini, and José Luis Verdegay, then Professor at the Department of Computer Science and Artificial Intelligence (DECSAI), of the University of Granada, Spain. 
In the ECSC Enrique headed the research unit on Collaborative intelligent systems, he established a connection with chemists who were interested in fuzzy logic, he was working in distributed AI. At the Open Workshop "Fuzziness and Medicine" as part of the I. International Symposium on Fuzziness, Philosophy and Medicine I organized at the ECSC on 23-25 March 2011, Enrique gave the keynote address "First Steps on Fuzzy Sets in Medicine." In this talk he combined his early research in biomedicine and brain research with his later work on the semantics of fuzzy logic. (see Fig. 7). Two and a half years later, Enrique left the center in November 2013 and due to the economic crisis, the ECSC had to be closed in 2016.

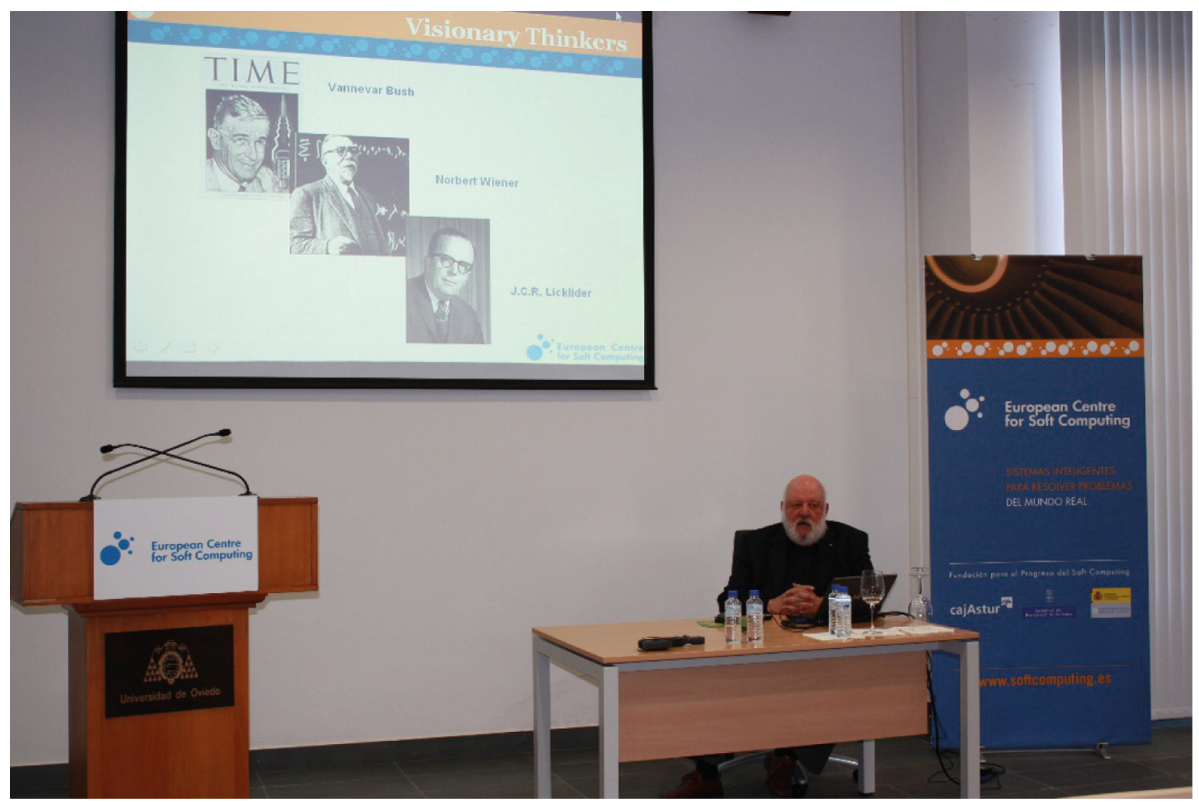

Fig. 7. Enrique during his talk "First Steps on Fuzzy Sets in Medicine" for the Open Workshop "Fuzziness and Medicine" at March 24 2013, ECSC, Asturias, Spain. (Photo: Rudolf Seising)

When I asked about the future of fuzzy logic and soft computing, also in light of the recently deceased Lotfi Zadeh, Enrique answered very optimistically in the interview: "We are going to continue!" Referring to the many technical applications with embedded CI technology, he pointed to the video camera pointed at him, he pointed out "anywhere we can see it, in those cameras that are filming us; in cars in appliances we have fuzzy logic. So, it had become part of the family. People who were skeptic about fuzzy logic, professors who were sceptic, now their students are applying fuzzy logic to of fuzzy logic, professors who were sceptic they have students who are applying fuzzy logic to problems. So, it has become imbedded and there is still a huge number of problems; for example in language understanding that would benefit from that. The important thing for people in academia by now is to keep on using fuzzy logic in their tool kit. ([1], 59:55-1:00:46) As a kind of tribute to Lotfi Zadeh and Richard Bellman 
he finished our interview. Regarding Lotfi Zadeh he said: "He was never somebody who said, well, here is fuzzy logic and that's it what you should use [...] No, he always said, here you have all these tools, probabilities, calculus of evidence, fuzzy logic, all sorts of methods. And that was incidentally, what I remember about Richard Bellman: He said: It is always better to have lots of methods and to try different methods and to see what kind of solutions you get. That gives you so much. So, fuzzy logic should remain in the tool kit and I see that it is entrenching there" ([1], 1:01:26).

Enrique was passionately committed to the various institutions of his scientific discipline, as treasurer, president, vice president and conference organizer. He was also a member of the CIS History Committee from the very beginning, because it was important to him that the historical development of computational intelligence not be forgotten and that young researchers learn about the history of their topics.

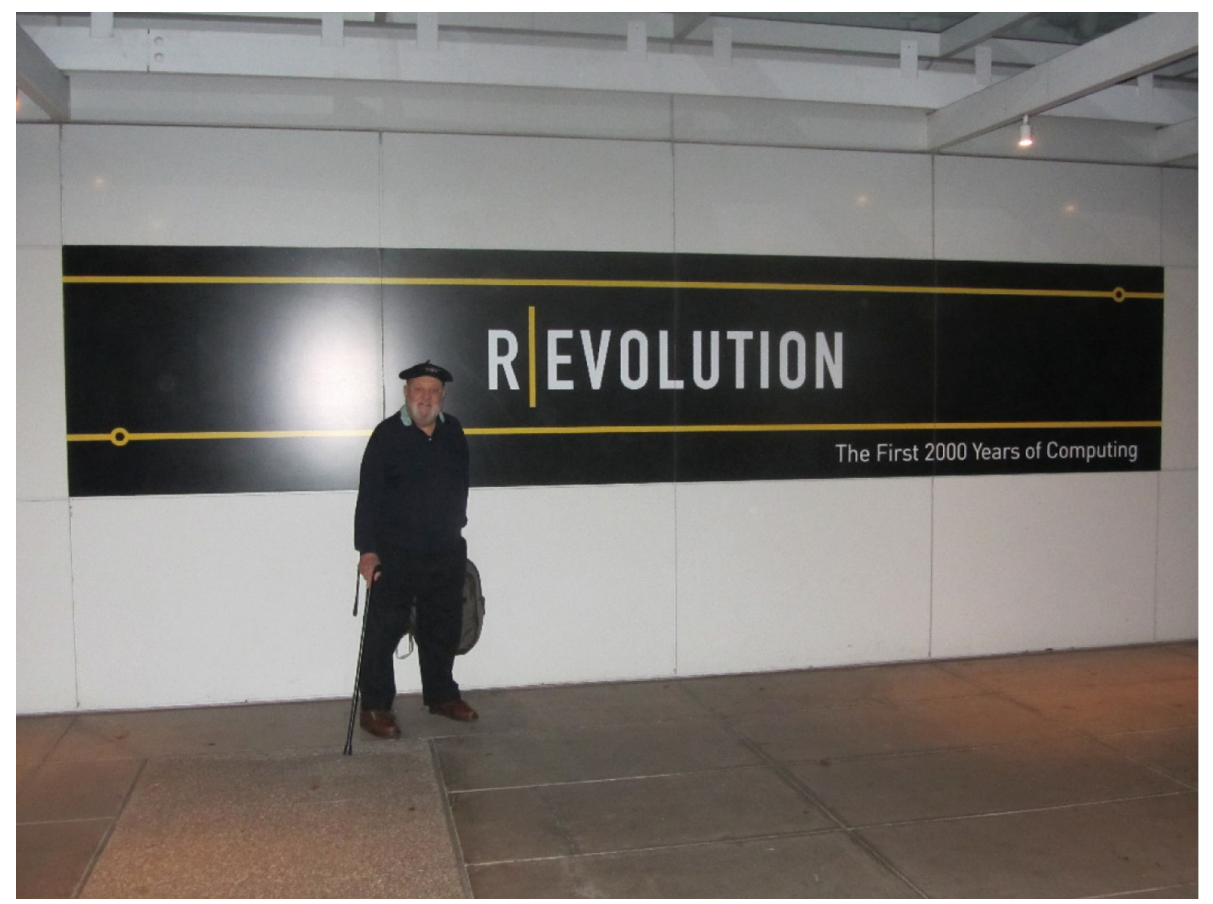

Fig. 8. Enrique Trillas at the entrance to the Computer History Museum in Mountain View, CA at February 16, 2017. (Photo: Rudolf Seising)

\section{References}

1. Seising, R.: Interview with Enrique Ruspini in Palo Alto. https://ieeetv.ieee.org/ns/ieeetvdl/ CIS/Ruspini_converted.mp4

2. Ruspini, E.H.: A theory of mathematical classification, Dissertation: Thesis (Ph.D.)University of California, Los Angeles-Engineering (1977) 
3. Ruspini, E.H.: A new approach to clustering. Inf. Control 15, 22-32 (1969)

4. Seising, R.: The Fuzzification of Systems. The Genesis of Fuzzy Set Theory and Its Initial Applications - The Developments up to the 1970s (STUDFUZZ 216) Springer, Berlin (2007). https://doi.org/10.1007/978-3-540-71795-9

5. Larsen, L.E., Ruspini, E.H., McNew, J.J., Walter, D.O.: A test of sleep staging systems in the unrestrained chimpanzee. Brain Res. 40, 319-343 (1972)

6. International Classification, vol. 3(2), pp. 98 (1976). Reports and Communications

7. Bezdek, J.: Interview with Enrique Ruspini, CIS Oral History Project Video (2011). https:// ieeetv.ieee.org/history/cis-history-enrique-ruspini-2011?rf=series $\mid 5 \&$

8. Seising, R.: On the History of Fuzzy Clustering: An Interview with Jim Bezdek and Enrique Ruspini, Archives for the Philosophy and History of Soft Computing, vol. 2, pp. 1-14 (2014). https://www.unipapress.it/it/book/aphsc-|-2-2014_168/

9. Seising, R.: On the history of fuzzy clustering: an interview with Jim Bezdek and Enrique Ruspini. IEEE Syst. Man Cybern. Mag. 1(1), 20-48 (2015)

10. Lasker, G.E. (ed.): Applied Systems and Cybernetics: Proceedings of the International Congress on Applied System Research and Cybernetics. Pergamon Press, Oxford (1981)

11. Bezdek, J., Ruspini, E.H.: The story of the NAFIP-1 poster. Arch. Philos. Hist. Soft Comput. 1(1), 1-5 (2018)

12. Ruspini, E.H.: Fuzzy logic in the Flakey robot. In: Proceedings of the International Conference on Fuzzy Logic and Neural Networks, lizuka (Japan) Fukuoka, pp. 767-770 (1990)

13. Saffiotti, A., Ruspini, E., Konolige, K.G.: A fuzzy controller For Flakey, an autonomous mobile robot. In: Reusch, B. (Hrsg.) Fuzzy Logic: Theorie und Praxis, 3. Dortmunder FuzzyTage Dortmund, 7-9, pp. 3-12. Springer, Heidelberg (1993). https://doi.org/10.1007/978-3642-78694-5_1

14. Ruspini, E.H.: Truth as utility: a conceptual synthesis. In: Proceedings of the Conference on Uncertainty in Artificial Intelligence, Los Angeles, CA, pp. 316-322 (1991)

15. Ruspini, E.H.: Approximate Reasoning: Past, Present, Future. Technical Note No. 4D2, Artificial In-telligence Center, SRI lnternational, Menlo Park, California, $19 \backslash 10$ (1991)

16. Ruspini, E.H.: On the semantics of fuzzy logic. Int. J. Approximate Reasoning 5, 45-88 (1991)

17. Seising, R., Trillas, E., Moraga, C., Termini, S. (eds.): On Fuzziness. A Homage to Lotfi A. Zadeh volume 2, chapter 87, (STUDFUZZ 299), pp. 598-609. Springer, Heidelberg (2013). https://doi.org/10.1007/978-3-642-35644-5

18. Ruspini, E.H.: ENRIC by Enrique. In: Seising, R. (ed.) Accuracy and Fuzziness. A Life in Science and Politics. SFSC, vol. 323, pp. 313-317. Springer, Cham (2015). https://doi.org/ 10.1007/978-3-319-18606-1_30 